\title{
Surgical Repair of Cyclodialysis Cleft
}

\author{
${ }^{1}$ Rajul S Parikh, ${ }^{2}$ Shefali R Parikh, ${ }^{3}$ Ravi Thomas \\ ${ }^{1}$ Bombay City Institute and Research Center, Mumbai, India \\ ${ }^{2}$ Lotus Eye Hospital, Mumbai, India \\ ${ }^{3}$ Queensland Eye Hospital, Queensland, Australia
}

\section{INTRODUCTION}

Cyclodialysis cleft is separation of meridonal ciliary muscle fibers from the scleral spur, thereby creating an additional drainage pathway of aqueous humor into the suprachoroidal space. ${ }^{1-4}$ This new drainage pathway leads to increase in uveoscleral outflow and may result in chronic ocular hypotony. ${ }^{5}$ The hypotony may also be due to decreased aqueous production. ${ }^{6}$ In past, creating an iatrogenic cyclodialysis cleft was used as one of the surgical option for the management of aphakic glaucoma. Cyclodialysis mostly occurs inadvertently during anterior segment surgery or due to blunt ocular trauma. ${ }^{2,7}$

The magnitude of the hypotony due to cyclodialysis cleft may not be proportional to the size of the cleft. ${ }^{5}$ As a result of ocular hypotony, patient may develop choroidal effusion, cystoid macular edema, optic nerve edema, engorgement and stasis of retinal veins, retinal folds, shallow anterior chamber, and cataract. Cystoid macular edema is one of the major contributing factor for visual loss due to hypotony caused by cyclodialysis cleft. If hypotony remains undetected and untreated for long time, visual loss may become permanent.

Ocular hypotony itself is the most frequent cause of ciliochoroidal detachment following cataract extraction. Therefore, prior to considering cyclodialysis cleft as a cause of hypotony, other causes like wound leak, retinal detachment, chronic inflammation, and anterior segment ischemia should be ruled out.

A careful gonioscopic examination of the anterior chamber angle is the key to the diagnosis of iatrogenic or traumatic cyclodialysis cleft. Sometimes it is difficult to see the cleft itself, as it is often small and obscured by a narrowed anterior chamber angle. A shallow chamber generally is caused by diffuse choroidal effusion due to hypotony that leads to forward displacement of the lens iris diaphragm.

It has been suggested that anterior chamber deepening by the injection of a viscoelastic agent into the anterior chamber may facilitate visualization of the cleft. ${ }^{8}$ High-resolution ultrasound biomicroscopy (UBM) is a good tool to diagnose and provide detailed information about the extent and location of a cyclodialysis cleft. ${ }^{9-11}$ UBM allows imaging of a cyclodialysis

cleft along its entire longitudinal and circumferential extent, with an accurate assessment of its location and size, regardless of gonioscopic visibility or patent cleft aperture. ${ }^{10,11}$ While gonioscopy allows evaluation only from the anterior face of the ciliary cleft, UBM provides cross sectional information of the iridocorneal angle.

Once the diagnosis of cyclodialysis is made, medical treatment consisting of topical 1\% atropine, 2 to 3 times daily should be attempted at-least for 6-8 weeks. Miotics and corticosteroids should be avoided. If the cleft is small in size $(<1 / 2$ clock hour) or no significant structural or functional abnormalities secondary to hypotony is seen, then, wait and watch along with medical treatment may be the best mode of action.

In small clefts, Argon laser therapy for repair of cyclodialysis can be tried. Various treatment options to close the cleft with laser has been described. ${ }^{3,12-17}$ It is assumed that, following laser treatment, edema of the choroid closes the cleft and blocks aqueous flow into the suprachoroidal space or perhaps the inflammation produced by laser treatment plays a role in altering the aqueous humor composition, thereby obstructing the drainage. $^{13}$

Other surgical options includes external transconjunctival cryotherapy at the presumed location of a cyclodialysis cleft, direct cyclopexy, ciliochoroidal diathermy, anterior scleral buckling, or vitreoretinal procedures. ${ }^{18-24}$ We usually reserve surgical intervention for those cases that do not respond to medical treatment. We prefer direct surgical cyclopexy (Cleft closure) to other surgical options.

\section{SURGICAL PROCEDURE}

Surgery is performed under General Anesthesia. First, through a paracentesis, a high molecular weight visco-elastic substance is injected into the anterior chamber to deepen the anterior chamber. This also raises the intraocular pressure (lOP) and hence facilitates the procedure. For closure of the cleft, it's exact localization is very important. We usually like to perform gonioscopy on operating table with help of direct goniolens 
(Koppes lens; Fig. 1) to confirm and to mark the cleft area on sclera with marker. The peritomy is performed. Subsequently, in the area of the cyclodialysis cleft, $4 \mathrm{~mm}$ posterior to limbus, partial thickness lamellar limbus-based scleral flap is raised (Fig. 2). Now, $1 \mathrm{~mm}$ posterior to scleral spur, at least $2 \mathrm{~mm}$ horizontal incision (the incision should be at-least $0.5 \mathrm{~mm}$ longer than the cleft) is placed over the remaining sclera (Fig. 3). At this location, the cyclodialysis cleft is directly visualized (Arrow in Fig. 3). In some cases, aqueous humor may ooze from the wound. The surface of the detached ciliary body may be cauterized with mild bipolar cautery. The ciliary body is reattached to the scleral spur under direct visual visualization by interrupted 8-0 nylon or 10-0 nylon sutures. This is accomplished by first passing the needle through the anterior sclera just posterior to the trabecular meshwork, then through the ciliary body avoiding the iris root, and again through the posterior scleral lip (Figs 4 and 5). Multiple sutures are taken till the cleft is completely closed (Fig. 6). Subsequently the partial thickness scleral flap is sutured with 10-0 nylon suture and conjunctiva is closed with 8-0 vicryl or 10- nylon suture (Fig. 7). We prefer 80 sutures as in some instances, after cleft closure, the IOP may

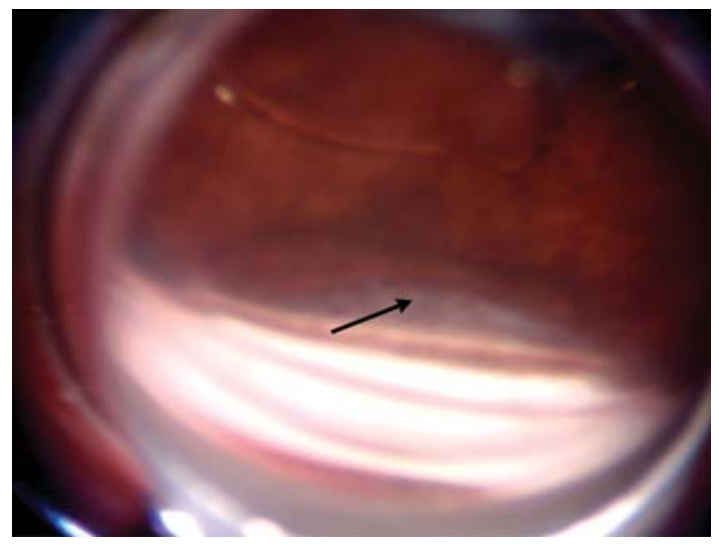

Fig. 1: Shows cyclodialysis cleft (Arrow showing cyclodialysis cleft in superior angle with direct gonioscope)

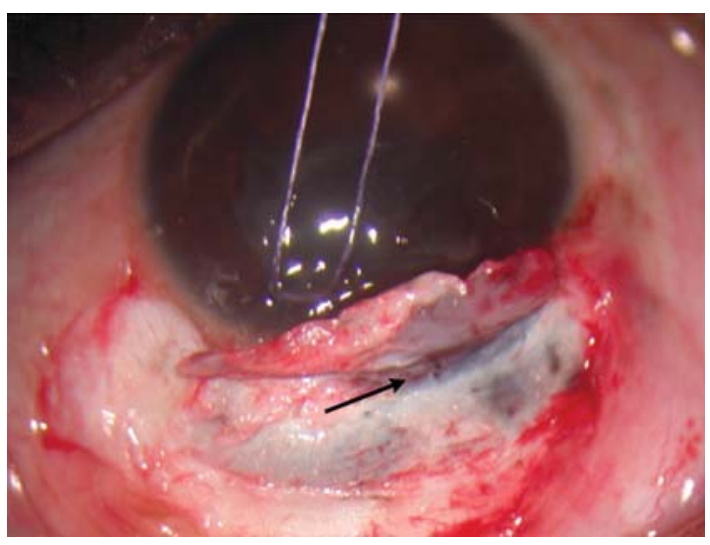

Fig. 2: Partial thickness scleral flap (Arrow showing partial thickness scleral flap at the site of cleft) increase to more than $60 \mathrm{~mm} \mathrm{Hg}$ and 10-0 nylon suture may bleed leading to reopening of cleft.

Figure 8 shows gonioscopy photograph of the same patient. The cleft is completely closed.

\section{POSTOPERATIVE MANAGEMENT}

Postoperatively patient is given systemic acetazolamide and topical cycloplegics, topical steroid. When the cyclodialysis cleft is closed, there may be a period of acute rise in IOP within first 2 weeks following the closure. This increase in IOP is caused by collapse of the aqueous drainage channels during the prolonged hypotony period and inability to reestablish drainage once the IOP is restored. Medical treatment with beta-blockers, carbonic anhydrase inhibitors, and hyperosmotic agents is indicated during the hypertensive stage. Miotics are contraindicated, as they could lead to opening of the cleft.

Treatment options are variable and with proper recognition and therapy, most of these patients may have restoration of ocular function and vision. If postoperatively ocular hypotony persists then clinician must suspect the incomplete closure of cyclodialysis cleft.

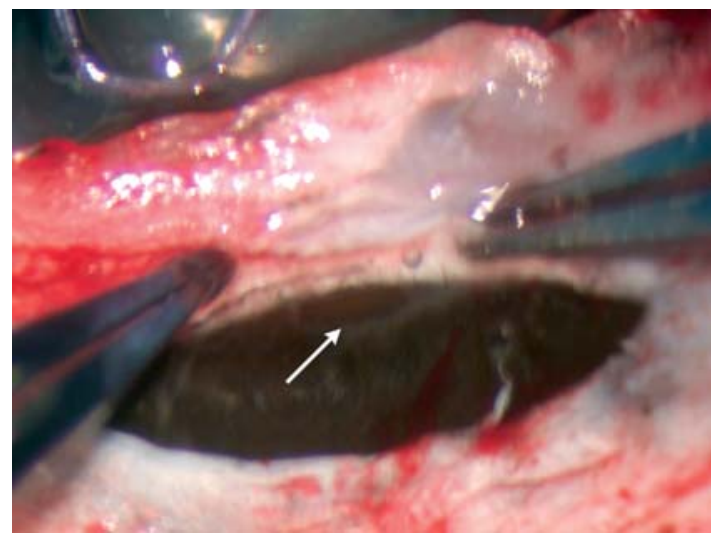

Fig. 3: Direct exposure of cyclodialysis cleft (Arrow showing cyclodialysis cleft)

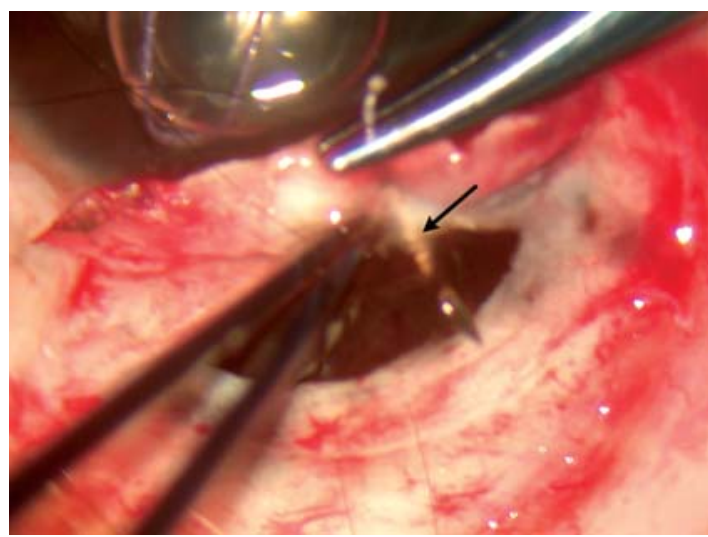

Fig. 4: Cleft closure (8-0 nylon suture is first passed from sclera and then from outer lip of cleft) 


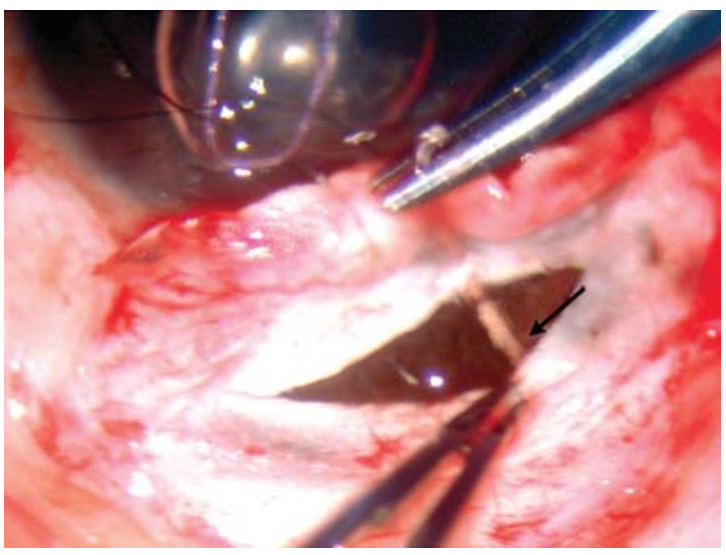

Fig. 5: Cleft closure (8-0 nylon suture is now passed from outer lip of cleft and then sclera)

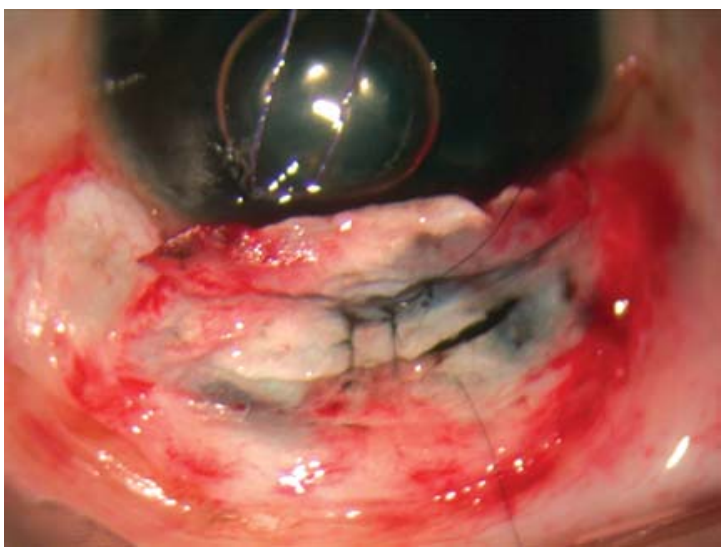

Fig. 6: Cleft closure (Multiple 8-0 nylon suture is tied to close the cleft completely)

\section{REFERENCES}

1. Maumenee AE, Stark GW. Management of persistent hypotony after planned or inadvertent cyclodialysis. Am J Ophthalmol. 1971;71:320-27.

2. Hansen SM, Laursen AB. Visualized cyclodialysis: an additional option in glaucoma surgery. Acta Ophthalmol (Copenh). 1986;64:142-45.

3. Partamian LG. Treatment of a cyclodialysis cleft with argon laser photocoagulation in a patient with a shallow anterior chamber. Am J Ophthalmol. 1985;99:5-7.

4. Wing GL, Schepens CL, Trempe CL, Weiter JJ. Serous choroidal detachment and the thickened choroid sign detected by ultrasonography. Am J Ophthalmol. 1982;94:499-505.

5. Viikari K, Touvinen E. On hypotony following cyclodialysis surgery. Acta Ophthalmol (Copenh). 1957;35:543.

6. Barkan O. Cyclodialysis: its mode of action. Arch Ophthalmol. 1950;43:793-96.

7. Slusher MM. Pseudophakic choroidal detachment with cyclodialysis cyst. Ophthalmic Surg. 1987;18:191-94.

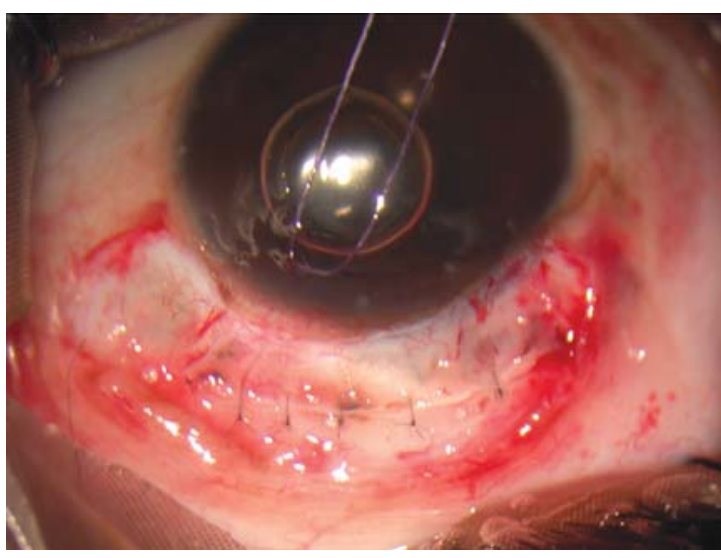

Fig. 7: Cleft closure

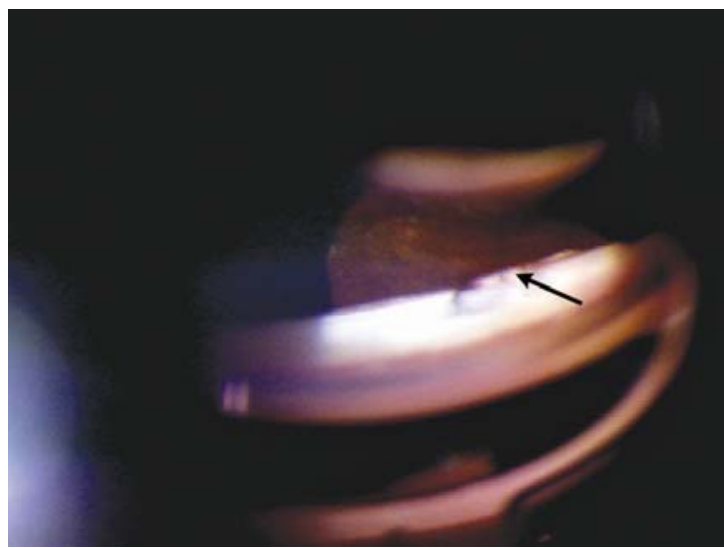

Fig. 8: Postoperative (First postoperative day, arrow shows closure of cleft)

8. Ormerod LD, Baerveldt G, Sunlap MA, Riekhof FT. Management of hypotonous cyclodialysis cleft. Ophthalmology. 1991;98:1384-93.

9. Gentile RC, Pavlin CJ, Liebmann JM, et al. Accurate diagnosis of traumatic cyclodialysis clefts by ultrasound biomicroscopy. Ophthalmic Surg 1996; 27:97-105.

10. Karwatowski WSS, Weinreb RN. Imaging of cyclodialysis cleft by ultrasound biomicroscopy. Am J Ophthalmol 1994;117:54143.

11. Endo S, Mitsukawa G, Fujisawa S, et al. Ocular ball bullet injury: detection of gonioscopically unrecognizable cyclodialysis by ultrasound biomicroscopy. Br J Ophthalmol 1999;83:1306.

12. Joondeph HC. Management of postoperative and post-traumatic cyclodialysis clefts with argon laser photocoagulation. Ophthalmic Surg. 1980;11:186-88.

13. Harbin TS Jr. Treatment of cyclodialysis clefts with argon laser photocoagulation. Ophthalmology. 1982;89:1082-83.

14. Aminlari A. Inadvertent cyclodialysis cleft. Ophthalmic Surg. 1993;24:331-34. 
15. Alward WM, Hodapp EA, Parel JM, Anderson DR. Argon laser endophotocoagulation closure of cyclodialysis clefts. Am J Ophthalmol. 1988;106:748-49.

16. Caronia RM, Sturm RT, Marmor MA, Berke SJ.Treatment of a cyclodialysis cleft by means of ophthalmic laser microendoscope endophotocoagulation. Am J Ophthalmol. 1999;128:760-61.

17. Brooks AM, Troski M, Gillies WE. Noninvasive closure of a persistent cyclodialysis cleft. Ophthalmology. 1996;103:194345.

18. Krohn J. Cryotherapy in the treatment of cyclodialysis cleft induced hypotony. Acta Ophthalmol Scand. 1997;75:96-98.

19. Vannas M, Bjorkemheim B. On hypotony following cyclodialysis and its treatment. Acta Ophthalmol (Copenh). 1952;30:63-64.

20. Kuchle M, Naumann GO. Direct cyclopexy for traumatic cyclodialysis with persisting hypotony: report in 29 consecutive patients [letter]. Ophthalmology. 1995;102:1413.

21. Tate GW Jr, Lynn JR. A new technique for the surgical repair of cyclodialysis induced hypotony. Ann Ophthalmol. 1978;10:1261-68.

22. Portney GL, Purcell TW. Surgical repair of cyclodialysis induced hypotony. Ophthalmic Surg. 1974;5:30-32.
23. Helbig H, Foerster MH. Management of hypotonous cyclodialysis with pars plana vitrectomy, gas tamponade, and cryoptherapy. Ophthalmic Surg Lasers. 1996;27:188-91.

24. Hoerauf $\mathrm{H}$, Roider J, Laqua H. Treatment of traumatic cyclodialysis with vitrectomy, cryotherapy, and gas endotamponade. J Cataract Refract Surg. 1999;25:1299-1301.

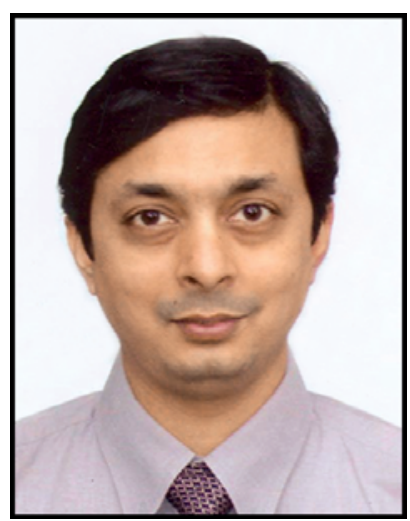

Rajul S Parikh (drparikhs@gmail.com)

"There are two powers in this world. One is justice and the other is forgiveness born out of mercy. Justice is good, but that which can be achieved by forgiveness cannot be had by justice" 